\title{
Rainfall induced erosion of soils used in earth roads
}

\author{
Esdras Ngezahayo ${ }^{1, *}$, Michael P.N. Burrow ${ }^{2}$, and Gurmel S. Ghataora ${ }^{2}$ \\ ${ }^{1}$ University of Birmingham, Civil Engineering Department, School of Engineering, B15 2TT, United Kingdom \\ ${ }^{2}$ University of Birmingham, School of Engineering, B15 2TT, United Kingdom
}

\begin{abstract}
Earth roads in rural areas of the developing world are key engines to the development of countries. They give access to education and health services, sustain agriculture and businesses, and promote social interactions between communities. However, earth roads suffer substantially from poor engineering and funding for construction and maintenance. Rainfall is probably their most dangerous enemy resulting in soil particle detachment leading to the loss of surface material. A laboratory rainfall simulator was used to identify the performance of an earth road surface compacted at the maximum dry density against rainfall energy and surface flow. Under the rain intensity of $30 \mathrm{~mm} / \mathrm{hr}$, erosion increased with rain duration from 0 to 30 minutes. Fine sand $(0.06-0.02 \mathrm{~mm})$ and medium sand $(0.02-0.6 \mathrm{~mm})$ particles eroded faster than coarse sand $(0.6-$ $2 \mathrm{~mm}$ ) and gravel $(>2 \mathrm{~mm}$ ) particles of the sediments collected at 5 minutes intervals of time. Additionally, a $20 \mathrm{~cm} \times 20 \mathrm{~cm}$ photograph at the same place was analysed using ImageJ software and showed reduction in number of particles from 18554 at $10 \mathrm{~min}$ to 5803 at $25 \mathrm{~min}$ as smaller particles had eroded in the meantime.
\end{abstract}

\section{Background}

About $80 \%$ of the world road networks are made of earth materials. It is estimated that in some developing countries the figure is greater than $90 \%$. For example in South Sudan more than $98 \%$ of the road network is unpaved [1]. Natural earth roads are constructed using compacted soils that make up the surface layer. Gravel roads require additional granular material that forms the uppermost layer of the road. In the developing world, earth roads may be the only method of communication. However, the importance of their role is not fully valued as they do not attract the required level of funding in terms of engineering and maintenance. As result, earth roads are very prone to the effect of adverse climate (rainfall, drought), which means that they can only be usable in the dry season. During the rainy season, earth roads can deteriorate, becoming muddy, slippery, with rills, gullies and potholes on the surface to a point where they are unusable.

Inadequate earth roads are the main contributor to poor transport statistics. For instance, only $37 \%$ of people in rural areas of developing countries have access to an all-weather road within $2 \mathrm{~km}$ compared to $94 \%$ in developed countries [2, 3, 4]. Sub-Saharan Africa is the most vulnerable region with a heavier burden of poor road network on women and children in countrysides [2]. One of the major problems that earth roads face is their erodibility due to rain and surface flow shear stresses. This has been confirmed by a systematic investigation of the erodibility of soils in rural roads undertaken at the University of Birmingham. According to the study, 78\% of rural roads failures are caused by rain erosion, the rest is mostly due to combined effects of traffic and human activities $[5,6]$.

The study also revealed that erosion in earth roads can be understood and mitigated to a certain extent. A laboratory-based study was undertaken to study movement of soil particles due to the impact of raindrops and water flows. This study can help to better understand the behaviour of materials that leads to improved designs of earth roads. Better understanding of erosion processes in earth roads can help the choice of good material for construction. The new surface soils must clearly provide good resistance to erosion stresses and adverse climate effects. Further best practices such as good construction, provision of efficient and effective drainage, and periodic maintenance can be an addition to the good material used for construction if all-season earth roads are to be achieved.

\section{Rainfall simulators for erosion tests}

Rainfall simulators were used for erosion testing of different purposes with the agricultural land management at the forefront $[7,8]$. Some of these have been effective for field and/ or laboratory tests. Field rainfall simulators are somewhat robust and difficult to be used in academic areas. However, small to medium sized rainfall simulators have been used successfully for laboratory erosion testing and produced results that compare favourably with field tests. Two types of rainfall simulators currently are in use, namely drop-forming simulators and pressurised simulators. These are briefly compared in Table 1 .

\footnotetext{
*Corresponding author : nesdras01@gmail.com
} 
Table 1. Drop-forming and pressurised simulators [7, 8].

\begin{tabular}{|c|c|c|}
\hline & $\begin{array}{l}\text { Drop-forming } \\
\text { simulator }\end{array}$ & $\begin{array}{c}\text { Pressurised } \\
\text { simulator }\end{array}$ \\
\hline Advantages & $\begin{array}{c}\text { Operational on } \\
\text { small plots and } \\
\text { hence suitable to } \\
\text { the laboratory } \\
\text { works. }\end{array}$ & $\begin{array}{l}\text { Suitable for both } \\
\text { laboratory / field } \\
\text { tests. Intensity/ } \\
\text { random raindrop } \\
\text { size as in natural } \\
\text { rainfall. }\end{array}$ \\
\hline Disadvantages & $\begin{array}{l}\text { High intensities } \\
\text { rarely found in } \\
\text { natural rain. } \\
\text { Drops form from } \\
\text { lower heights } \\
\text { with difficulty to } \\
\text { achieve terminal } \\
\text { velocities. }\end{array}$ & $\begin{array}{l}\text { In addition to } \\
\text { complex designs } \\
\text { related to the rain, } \\
\text { the portability of } \\
\text { the simulator } \\
\text { offers challenge. }\end{array}$ \\
\hline
\end{tabular}

\section{Methodology}

\subsection{Soil material selection}

The choice of the soil was based on its properties recommended for the construction of earth roads [9] and the criteria for soil erosion testing [10]. Accordingly, a well-graded soil material with good particle packing that leads to higher density and thus high bearing capacity for the earth road to withstand traffic loadings is desirable. This will provide better support to traffic and reduce the amount of earth road deformations that would result from vertical loadings. In addition, recommended plasticity index $(\mathrm{PI})$ for earth road material ranging from $2 \%$ to $10 \%$ [9] must be ensured to increase cohesion between particles. [11] say that in practice, it is possible to have plasticity indices greater than $10 \%$, but those will cause the road to be more slippery in the rainy seasons and dustier in the dry seasons. Such a soil was prepared by mixing building sand and china clay and satisfied the recommendations from [10] for erosion testing as in the Table 2 below.

Table 2. Criteria for soils to use in erosion tests [10].

\begin{tabular}{c|lll}
\hline Particle (mm) & Clay & Loam & Sand \\
\hline $\mathrm{d}_{15}$ & $>0.0015$ & $>0.05$ & $>0.001$ \\
$\mathrm{~d}_{50}$ & $0.001-0.1$ & $0.01-1.0$ & $0.8-2.0$ \\
$\mathrm{~d}_{85}$ & $0.01-1.0$ & $0.5-5.0$ & $1.0-10$ \\
$\mathrm{~d}_{100}$ & $<10$ & $<25$ & $<40$ \\
\hline PI $(\%)$ & $>14$ & $1.0-8.0$ & - \\
\hline
\end{tabular}

The mixing of the poorly graded building sand (maximum dry density, $1.84 \mathrm{Mg} / \mathrm{m}^{3}$ and optimum moisture content, $13 \%$ ) and its $5 \%$ china clay resulted in a sandy soil of properties indicated in the Table 3 . This soil matches the criteria for erosion testing for a loam soil class according to $[10]$.
Table 3. Properties of the synthesised soil.

\begin{tabular}{l|l}
\hline Soil property and unit & Value \\
\hline $\mathrm{d}_{15}(\mathrm{~mm})$ & 0.26 \\
$\mathrm{~d}_{50}(\mathrm{~mm})$ & 0.45 \\
$\mathrm{~d}_{85}(\mathrm{~mm})$ & 2.1 \\
$\mathrm{~d}_{100}(\mathrm{~mm})$ & 10.3 \\
Plasticity index (\%) & 5.2 \\
Fines $(\%)$ & 5 \\
Sand $(\%)$ & 81 \\
Gravel $(\%)$ & 14 \\
Bulk density $\left(\mathrm{Mg} / \mathrm{m}^{3}\right)$ & 2.25 \\
Maximum dry density $\left(\mathrm{Mg} / \mathrm{m}^{3}\right)$ & 2.06 \\
Optimum moisture content $(\%)$ & 9.3 \\
\hline
\end{tabular}

\subsection{Rain simulator design}

The pressurised rain simulator suitable for laboratory works was developed to give rainfall intensities ranging from $20 \mathrm{~mm} / \mathrm{hr}$ to $151 \mathrm{~mm} / \mathrm{hr}$. A rain intensity of 30 $\mathrm{mm} / \mathrm{hr}$ recurrent for more than 50 min every two years in tropical countries was taken as the worst-case scenario $[12,13]$. The rain simulator was constructed using $15 \mathrm{~mm}$ $x 1.5 \mathrm{~mm}$ BARRIER PE-X pipes according to [14]. The pipes were spaced at $5 \mathrm{~cm}$ over the length of $60 \mathrm{~cm}$ and width of $30 \mathrm{~cm}$ of the soil to be tested. To achieve this small spacing between pipes, two sets of pipes were superimposed since the connectors usually allowed $10 \mathrm{~cm}$ spacing, and connected by crossing - horse pipes at one end to ensure that both sets of pipes are supplied with water evenly and at the same time. Moreover, each pipe was perforated, and 15 nozzles spaced by $1.5 \mathrm{~cm}$ were fixed in the holes to allow drops to form over the soil testing box. The height of the falling raindrop was $2 \mathrm{~m}$ above the surface of the soil in the test box as in the Fig.1. Water was supplied from the water tab through the horse pipe and the flow meter that allows to calibrate the desired rain intensity. The design rain intensity was with the following properties:

The Coefficient of uniformity $(\mathrm{Cu})$ of the rainfall: before testing soil erosion using a rainfall simulator, there must be assurance that the raindrops fall uniformly over the tested surface. Uniformity of the rainfall over the tested soil was checked by placing eight $250 \mathrm{ml}$ graduated measuring cylinders across the surface of the tested soil that was covered by a transparent plastic sheet. The rainwater for various flowrates was collected over a period of $5 \mathrm{~min}$ and then $\mathrm{Cu}$ calculated using the Christiansen formula [15]. Usually, $\mathrm{Cu}$ must be greater than $80 \%$ and, in this case it was found to be $100 \%$. The Christiansen formula is:

$$
C u=100\left[1-\left(\sum / D i-D a v /:(n-D a v)\right)\right]
$$

$\mathrm{Cu}$ : uniformity of rainfall over the area (\%) 
Di: depth of water in the cylinder $(\mathrm{cm})$

Dav: average rain depth in cylinders, $(\mathrm{cm})$

$\mathrm{n}$ : number of cylinders.

The size of rain drops (d) was checked using the flour method as suggested by [16]. Average rain drop size was found to be $4.6 \mathrm{~mm}$ (diameter). Raindrop's terminal velocity $(\mathrm{V})$, determined according to [10], of a $4.6 \mathrm{~mm}$ raindrop falling from $2 \mathrm{~m}$ was approximately $5.55 \mathrm{~m} / \mathrm{s}$. Kinetic energy (KE); considering raindrops as spheres, was calculated based on equation (2) [17], where $\mathrm{m}=$ mass of the raindrop. Based on mass of raindrop of 51 milligrams (assumes sphere of $4.6 \mathrm{~mm}$ diameter), KE was estimated to be 771 micro-joules:

$$
\mathrm{KE}=0.5 \mathrm{mV}^{2}
$$

Based on work done by [18], it was estimated that the kinetic energy of $4.6 \mathrm{~mm}$ droplet falling through $2 \mathrm{~m}$ is enough to initiate detachment in soils with $\mathrm{d} 50 \leq 1.0 \mathrm{~mm}$. Those detached particles can then be transported by surface water. The rain energy usually dominates the detachment until when the surface flow thickness becomes significant for the detachment to depend only on the flow shear stresses. Usually, the amount of shear stresses developed depends on both the amount of rain and the road geometry [19]. Normally, shear stresses and soil properties such as plasticity, roughness, compaction levels as well as effects of traffic and climate cycles of wetting and drying determine the magnitude of erosion rates in earth roads [20].

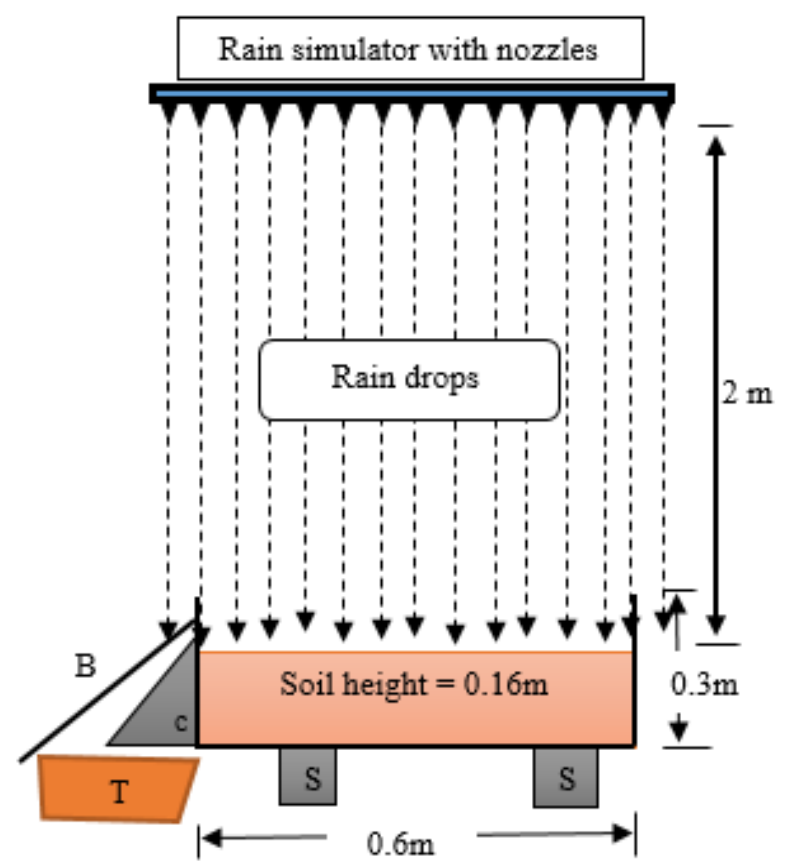

Fig. 1. Side view of the rain simulator and the soil box (S: supports of the box; $\mathrm{T}$ : tray for sediment collection and $\mathrm{B}$ : barrier to prevent outsiders drops to fall into the tray and C: gutter that conveys sediment into $\mathrm{T}$ ).

\subsection{Soil testing box design}

Erosion tests were conducted on a range of testing boxes and flumes of different sizes from $0.5 \mathrm{~m} \times 0.05 \mathrm{~m} \times 0.12 \mathrm{~m}$ to $22 \mathrm{~m} \times 0.4 \mathrm{~m} \times 0.76 \mathrm{~m}$ length, width and height respectively [19]. Accordingly, the soil was compacted at the dry density of $2.06 \mathrm{Mg} / \mathrm{m}^{3}$ into the test box measuring $0.6 \mathrm{~m} \times 0.3 \mathrm{~m}$ to a height of $0.16 \mathrm{~m}$. The test box was $0.3 \mathrm{~m}$ high to allow water to flow without spillage. This was only an exception at the exit where the box wall must be equal to the soil height for a free motion of both the flow and the sediment to the gutter.

\section{Results}

Five erosion tests were performed under same rain intensity, slope $(0 \%)$, compaction levels and duration. Results agreed on the amount of both runoff and sediment content, but their averages were presented to count for observed small differences. Repeatability was very good with a variation in quantity of sediment of less than $2 \%$ amongst all the results. As the focus was only on sediment, two types of results were analysed. Firstly, sediment collected at 5-minutes intervals was oven-dried for $24 \mathrm{hrs}$ before dry sieving. This showed differences in particle size distributions for different sediments as shown in Fig.2. Additionally, the analysis of fractions of sediments was done to track the behaviour of those fractions as erosion test goes on. This is shown in Fig. 3.

Secondly, a $20 \mathrm{~cm} \times 20 \mathrm{~cm}$ portion of the surface of the test soil was photographed at 10 and 25 min from the start of the test. The images were then analysed for particles number and size using ImageJ Software [21]. Since the area for analysis remained the same, 3 scenarios were possible:

(a) the number of particles reduces with time and there is increase in overall diameter of particles appearing on the surface, which means that smaller particles erode faster than bigger sized ones,

(b) the number of particles appearing on the surface increases and their overall diameter decreases to mean that bigger sized particles erode faster than smaller ones,

(c) both the number and size of particles on the surface remain unchanged with time, therefore there is equal rate of erosion for all particle sizes.

The Fig. 4 and Fig. 5 show that scenario (a) was observed between $10 \mathrm{~min}$ and $25 \mathrm{~min}$ of erosion test. Event hough the low resolution camera (PANASONIC, DMC-TZ60, LUMIX) used during the study did not allow the capture of particles smaller than $0.2 \mathrm{~mm}$ diameter, and hence all smaller particles considered as equal to this size by the software, results should not be compromised as not only these particles were only about $6 \%$ in the tested soil, but also mostly eroded before $10 \mathrm{~min}$, time at which photographs were taken. 


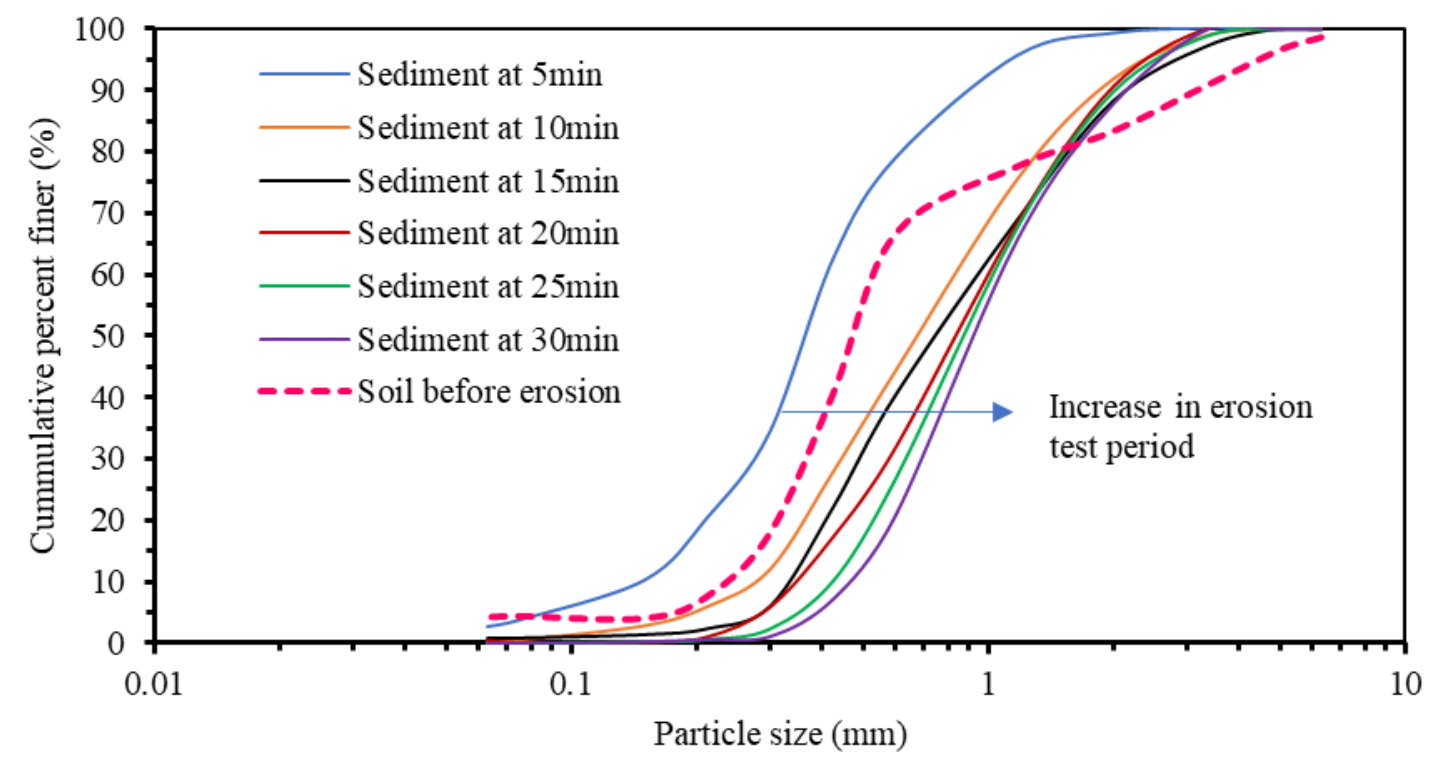

Fig.2. PSD of investigated soil and sediments collected at 5 min interval periods during erosion test.

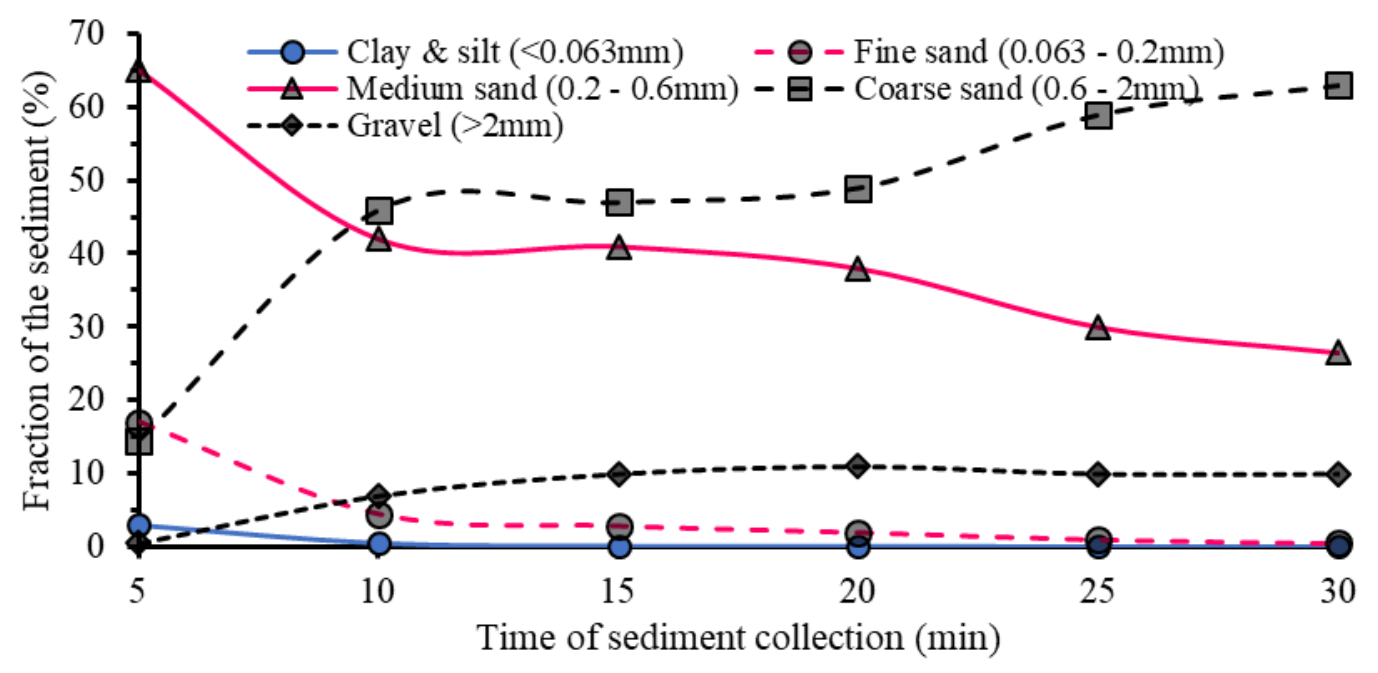

Fig.3. Changes in main fractions of sediments with time during erosion test.

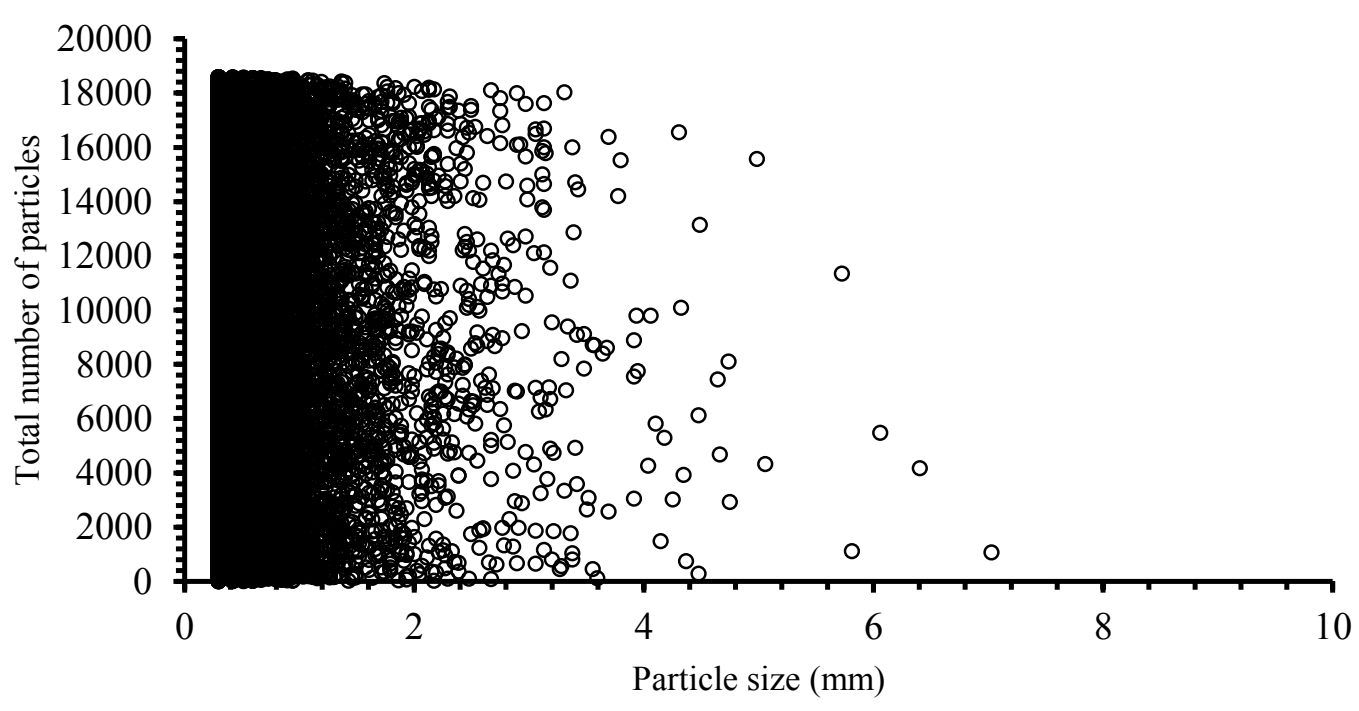

Fig. 4. Number and size of particles for a photograph taken at 10 min of erosion test. 


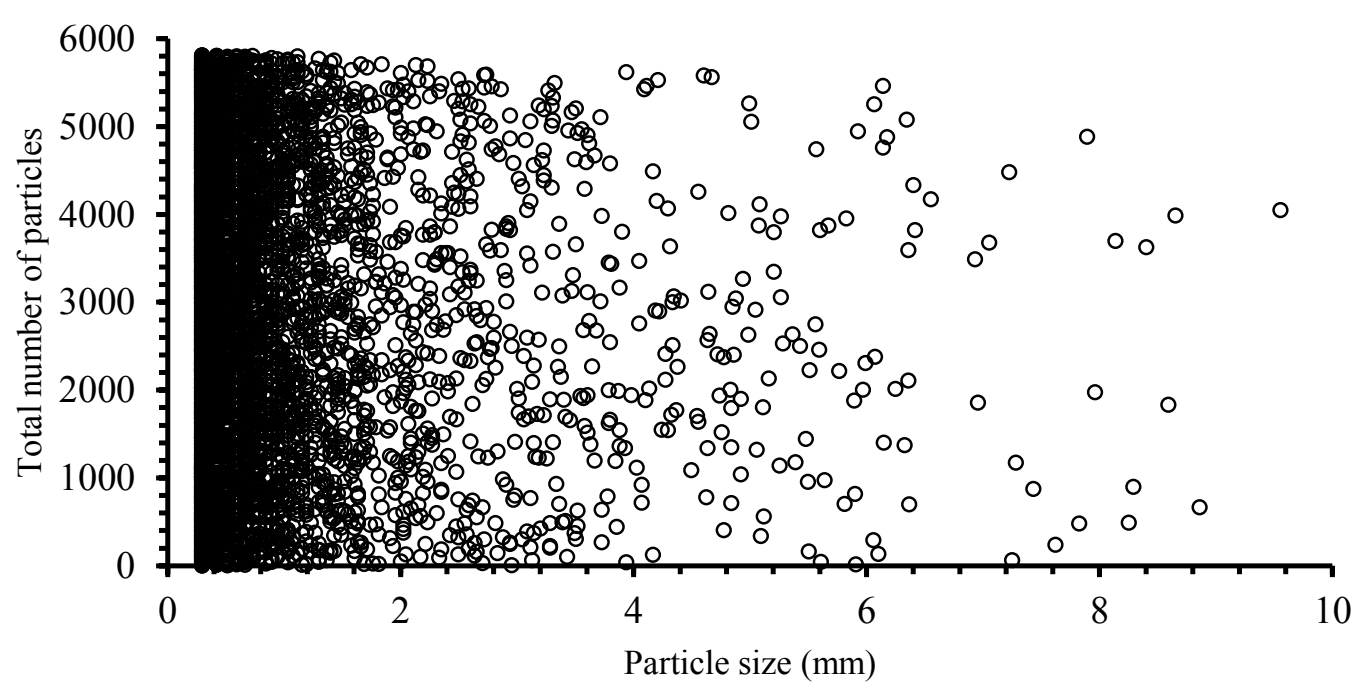

Fig.5. Number and size of particles for a photograph taken at 25 min of erosion test.

\section{Discussions of results}

\subsection{Collected sediment}

The analysis of particle size distribution of sediments showed similar results to all the five samples. Finer particles such as clay and silt eroded in the first $5 \mathrm{~min}$ as evidenced by cloudiness of water. This was obvious in the sediment flow at $5 \mathrm{~min}$ that was dirtier than the one at 10 min despite it being collected in 3 min only since the first 2 min were for samples saturation after which the flow started. Small granular particles were detached by falling rain; either removed on the surface or splashed to the walls of the testing box, which, except at the exit, extended $14 \mathrm{~cm}$ above the soil surface to ensure that no splashed particles could escape from it. Those on the box walls would later join the flow, pushed by the raindrops when the increased flow thickness reduced the effect of the rain energy to the soil surface.

Only the sediment collected at 5 min fully plotted to the left side of the tested soil curve while other sediments collected at different times partly plotted to its right and partly to its left. This shows that fine particles reduced gradually in the sediment as erosion testing period increases while bigger particles increased. Fine particles eroded from the tested soil, leaving sand and gravel particles with more degree of freedom and mobility under the effect of water flows. The fact that early collected sediment generally plots to the left side of the next collected sediment means that the smaller the particle, the easier and faster it will be eroded. From Fig.3, clay and silt fraction eroded completely in the first $10 \mathrm{~min}$. The fine sand fraction in sediments reduced from $17 \%$ at 5 min to $0.5 \%$ at $30 \mathrm{~min}$. In the same time, medium sand fraction reduced from $65 \%$ to $26.5 \%$. On the other hand, coarse sand fraction increased gradually from $14.5 \%$ to about $63 \%$ and the gravel fraction that was predominantly fine gravel $(2-6 \mathrm{~mm})$ increased from $0.5 \%$ to about $11 \%$.

\subsection{Photographs}

Two photographs were taken at $10 \mathrm{~min}$ and $25 \mathrm{~min}$ of the erosion testing and a $20 \mathrm{~cm} \times 20 \mathrm{~cm}$ square from the same place of those photographs were analysed using ImageJ software. The later helped to visualise soil particles in a 2-dimentional view for their size fraction analysis. Results showed that the number of soil particles in the square reduced from 18554 to 5803 between the $10^{\text {th }}$ and the $25^{\text {th }}$ min. If the particles top views are circles, calculations showed that their mean diameter increased from $1.6 \mathrm{~mm}$ to about $2.9 \mathrm{~mm}$ during the same period as in the Fig. 6 .

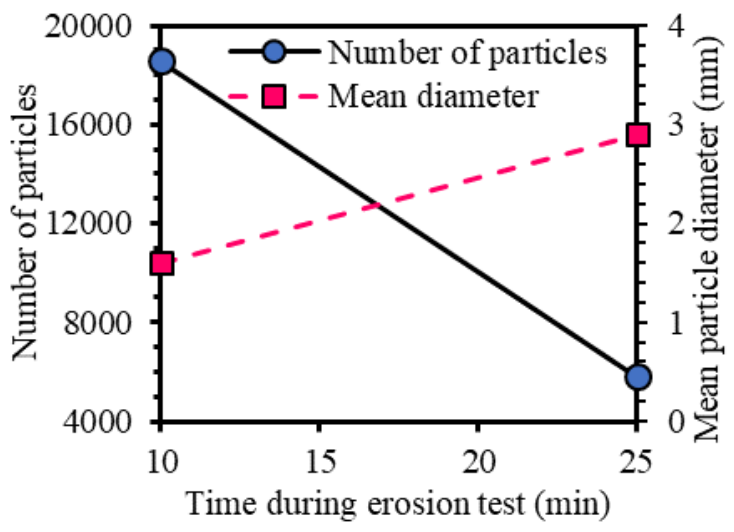

Fig.6. Surface soil particles behaviour during erosion test

\section{Conclusions}

A rainfall simulator was used for erodibility tests on the compacted granular soil. The results from particle size analysis of the sediment collected at $5 \mathrm{~min}$ time intervals up to $30 \mathrm{~min}$ and the analysis of particle behaviour within a $20 \mathrm{~cm} \times 20 \mathrm{~cm}$ square portion of the photographs taken at $10 \mathrm{~min}$ and $25 \mathrm{~min}$ of rainwater erosion test advanced the understanding of erosion mechanisms in earth roads. Erodibility of soils depends on various soil properties, but particle size may be the most important. This study 
showed that in a compacted granular soil; fine-grained particles of clay, silt and sand eroded faster than bigger soil particles of sand and gravel. Majority of the clay and silt size particles eroded from the surface in about the first 10 minutes of rainfall. Fine sand also eroded in about the first 10 minutes. With the loss of fines, surface gradually became occupied by coarser particles. The loss of surface material due to rainfall erosion may cause other road surface defects such as deformations, potholes, rills and gullies that, if not addressed in due time may permanently destroy the road.

The authors wish to acknowledge the support of the Commonwealth Scholarship Commission in the UK for this research.

\section{References}

1. The World Factbook, Field Listing: Roadways-CIA https://www.cia.gov/library/publications/the-worldfactbook/fields/2085.html, (2017)

2. World Bank, Safe, Clean and Affordable Transport for Development. The WB Group's Transport Business Strategy 2008 - 2012 (2008).

3. African Monitor - DSM, Unlocking the African Moment-Rural infrastructure in Africa, Paper series, www.africanmonitor.org/wpcontent/uploads/2017/.../African-Monitor-DSM2012.pdf, (2012)

4. M. Torero, S. Chowdhury, Increasing access to infrastructure for Africa's rural poor. IFPRI: 2020 Africa Conference Brief, Workshop 16. ageconsearch.umn.edu/bitstream/45763/2/ib32.pdf, (2005)

5. A.D. Ziegler, T.W. Giambelluca, M.A. Nullet, R.A. Sutherland, S. Yarnasarn, J. Pinthong, P. Preechapanya, S. Jaiaree. Towards understanding the cumulative impacts of roads in upland agricultural watersheds of northern Thailand. Agr., Ecosy. Envir., 104 (2004).

6. A.D. Ziegler, T.W. Giambelluca, R.A. Sutherland, T.T. Vana, M.A. Nullet. Horton overland flow contribution to runoff on unpaved mountain roads: Case study in northern Thailand. Hydr. P. 15 (2001).

7. R.A. McLaughlin, T.T. Brown, 2006. Evaluation of Erosion Control Products With and Without Added Polyacrylamide. JAWRA, 42, 3 (2006).

8. L.C. Kibet, L.S. Saporito, A.L. Allen, E.B. May, P.J.A Kleinman, F.M. Hashem, R.B. Bryant, A Protocol for Conducting Rainfall Simulation to Study Soil Runoff. J. Vis. Exp. 86, e51664, doi:10.3791/51664 (2014).

9. G. Keller, J. Sherar. Low-Volume Roads Engineering. Best Management Guide, USID (2003)

10. ASTM (2015). Standard Test Method for Determination of Rolled Erosion Control Product Performance in Protecting Hillslopes from RainfallInduced Erosion. West Conshohocken, PA, 1-10.

11. Association of Southern African National Road Agencies, Guidelines for Use of Sand in Road
Construction in the SADC Region, https://assets.publishing.service.gov.uk/media/57a08 a39e5274a27b20004bb/AFCAP-GEN028-C-Sandin-Road-Construction-Final-Guideline.pdf, (2013)

12. N. Wagesho, M. Claire. Analysis of Rainfall Intensity-Duration-Frequency Relationship for Rwanda. J.W.R.P., 8 (2016).

13. B. Mohymont, G. R. Demarée, D. N. Faka. Establishment of IDF-curves for precipitation in the tropical area of Central Africa - comparison of techniques and results. N.H.E.S.S, 4, 3 (2004), Copernicus Publ. on behalf of the E. Geosc. Union.

14. BS 7291-3:2010. Thermoplastics and Fitting systems for hot and cold water for domestic purposes and heating installations in buildings. Specification for crosslinked polyethylene (PE-X) pipes and associated fittings.

15. J. P. Christiansen, "Irrigation by Sprinkling" University of California Agricultural Experiment Station, Bulletin No. 670, 124 (1942).

16. J. D. Eigel, I. D. Moore, "A Simplified Technique for Measuring Raindrop Size and Distribution." Trans. ASABE, 26, 4 (1983).

17. J. B. Humphry, T. C. Daniel, D. R. Edwards, A. N. Sharpley, A Portable Rainfall Simulator for PlotScale Runoff Studies, Applied Engineering in Agriculture, ASAE, 18(2):199-204 (2002)

18. C. Salles, J. Poesen, G. Govers (2000). Statistical and physical analysis of soil detachment by raindrop impact : Rain erosivity indices and threshold energy. Water Res. Res., 36, 9 (2000).

19. A. Knapen, J. Poesen, G. Govers, G. Gyssels, J. Nachtergaele, Resistance of soils to concentrated flow erosion: A review. Earth-Sc. Rev., 80 (2007).

20. R.B. Bryan, "Soil erodibility and processes of water erosion on hillslope," J. Geomorphol., 32, 385-415 (2000)

21. T. Ferreira, W. Rasband, ImageJ User Guide, IJ1.46r, https://imagej.nih.gov/ij/docs/guide/user-guide.pdf, (2012). 